\title{
INTERPRETACIONES DE LA ENCUESTA MAPUCHE DEL CEP
}

\author{
Carolina Segovia y Lucas Sierra*
}

$\mathrm{D}_{\mathrm{e}-\mathrm{s}}$ esde distintos ángulos de análisis, seis artículos exploran en esta edición de Estudios Públicos los resultados de la encuesta que el CEP aplicó en 2006 a la población mapuche urbana y rural de Chile ${ }^{1}$. Antes de presentar los artículos, unas palabras sobre esta encuesta.

\section{La encuesta}

El objeto de esta encuesta fue producir información que pueda ayudar a conocer mejor el mundo mapuche hoy y que pueda contribuir, por lo mismo, a configurar una mejor política pública en materias indígenas ${ }^{2}$.

La aplicación de la encuesta fue precedida de un largo estudio para la confección del instrumento. En esta tarea contamos con la valiosa ayuda

* Investigadores del CEP.

Agradecemos a Ingrid Haarr por su ayuda en la edición de las referencias bibliográficas de los artículos sobre la encuesta mapuche que se publican en este número.

${ }^{1}$ CEP, "Estudio de Opinión Pública. Los Mapuche Rurales y Urbanos Hoy. Mayo 2006”, disponible en forma íntegra en www.cepchile.cl Próximamente aparecerá publicado en el Documento de Trabajo No 367 (2007) del Centro de Estudios Públicos.

2 El año 2006 el CEP, además, publicó dos libros sobre la lengua mapuche: Adalberto Salas, El Mapuche o Araucano: Fonología, Gramática y Antología de Cuentos, segunda edición, y Fernando Zúñiga, Mapudungun: El Habla Mapuche. 
de los siguientes especialistas: Carlos Aldunate, Jaime Andrade, Rolf Foerster, Ignacio Irarrázaval, Leonel Lienlaf, Aldo Mascareño y Osvaldo Silva.

La encuesta interrogó sobre un vasto conjunto de cuestiones. Por ejemplo, sobre los problemas a los cuales el gobierno debería prestar atención; sobre la forma en que son evaluadas diferentes instituciones (nacionales y mapuche); sobre distintas dimensiones de la cultura y de la identidad tales como el conocimiento y uso de la lengua mapuche, y el conocimiento y participación en ritos y ceremonias; sobre las perspectivas de la vida en el campo, en la ciudad y la migración entre ellos, sobre el significado de la tierra y la percepción del conflicto que en torno a ella se viene esporádicamente produciendo, entre varias otras cuestiones.

La recolección de datos se realizó entre el 29 de abril y 31 de mayo de 2006. Fueron encuestadas en sus hogares 1.487 personas mayores de 18 años que se autodefinieron como mapuche. Simultáneamente, se entrevistó a 1.484 personas que no se autodefinieron como mapuche y que viven en los mismos lugares que los mapuche. Ésta es una muestra de control que representa a los “vecinos” de aquellos entrevistados que sí se autodefinen como tales ${ }^{3}$. Las regiones cubiertas fueron la Metropolitana, Octava, Novena y Décima. De acuerdo al último Censo, del año 2002, éstas agrupan al 90 por ciento de la población que en Chile se autodefine como mapuche. Se encuestó en el campo y en la ciudad. La distribución de la población mapuche y de la muestra se observa en el siguiente cuadro:

PROPORCIÓN DE LA POBLACIÓN MAPUCHE Y ESTRUCTURA DE LA MUESTRA (\%)

\begin{tabular}{lccc}
\hline Región & $\begin{array}{c}\text { Población mapuche } \\
\text { total }\end{array}$ & $\begin{array}{c}\text { Población mapuche } \\
\text { urbana }\end{array}$ & $\begin{array}{c}\text { Población mapuche } \\
\text { rural }\end{array}$ \\
\hline Del Bío-Bío & 9,1 & 6,3 & 2,8 \\
De la Araucanía & 34,9 & 9,3 & 25,6 \\
De Los Lagos & 19,0 & 8,7 & 10,3 \\
Metropolitana de Santiago & 37,0 & 36,4 & 0,5 \\
Total & 100 & 60,7 & 39,3 \\
\hline
\end{tabular}

${ }^{3}$ El universo considerado para la selección de la muestra mapuche está constituido por 370.975 personas de 18 años y más, que, en esas cuatro regiones, se declaran mapuche. El resto de la población mapuche se encuentra disperso a lo largo del territorio nacional. El universo, entonces, está compuesto por 370.975 personas de 18 años y más, que se declaran mapuche en las regiones mencionadas anteriormente. Toda la información sobre esta encuesta, incluyendo los datos, el diseño metodológico, el cuestionario completo y el diccionario de variables, está disponible en www.cepchile.cl 
Éste es un esfuerzo inédito en Chile. Nunca antes se había hecho un estudio de la población mapuche de esta cobertura. Considera, además, a la población urbana mapuche, que constituye el 60 por ciento de toda la población mapuche en Chile. Esto es interesante porque hasta ahora la política pública en estas materias parece estar básicamente enfocada en el campo. También es interesante la muestra de control que se incorporó para conocer la opinión de los vecinos que no se definen a sí mismos como mapuche.

\section{Los artículos}

Una vez que los resultados de la encuesta fueron procesados, el CEP encargó a seis especialistas calificados que interpretaran algunos de los datos recogidos ${ }^{4}$. Fernando Zúñiga, lingüista, explora el estado de cosas con la lengua mapuche en su artículo "Mapudunguwelaymi am? ‘¿Acaso Ya No Hablas Mapudungun?’ Acerca del Estado Actual de la Lengua Mapuche”. La principal conclusión, dice su autor, es que "el mapudungun parece encontrarse en un estado de precariedad sociolingüística, y que sólo políticas públicas e iniciativas privadas que conduzcan a una revitalización efectiva y eficaz en el corto plazo lograrán salvar a la lengua de la extinción inminente”.

Eduardo Valenzuela, sociólogo, escribió “Tierra, Comunidad e Identidad Mapuche”, en el que identifica la lengua y la tierra como los factores más determinantes de la identidad mapuche, junto con notar también un deterioro importante en el uso de la lengua mapuche y una pérdida de fuerza de la comunidad ritual y de la comunidad de sangre.

Ignacio Irarrázaval, geógrafo, y María de los Ángeles Morandé, socióloga, escribieron "Cultura Mapuche: Entre la Pertenencia Étnica y la Integración Nacional”, en el que se advierte la coexistencia de una pertenencia más bien simbólica a la cultura ancestral con anhelos reales de integración a la cultura nacional en el sentir mapuche. También avanzan algunos criterios de política pública.

El trabajo del sociólogo Aldo Mascareño, "Sociología de la Cultura: La Deconstrucción de lo Mapuche”, reflexiona sobre el concepto sociológico de cultura, criticándolo a propósito de los datos de la encuesta. En el mundo mapuche, señala el autor, la cultura "cumple una función política: construye una ficción de unidad en un mundo fragmentado que, como un mana, es adosable a cualquier reivindicación política. Es decir, en términos

${ }^{4}$ Los borradores de todos los artículos fueron presentados y discutidos en seminarios públicos que el CEP organizó los días 30 de noviembre y 19 de diciembre de 2006. 
sociológicos, cultura para poco; en términos políticos, cultura para mucho”. Esta tesis es discutida por Jorge Larraín, sociólogo, en una nota que se publica a continuación del artículo de Aldo Mascareño.

La selección termina con dos miradas más antropológicas, una de ellas comparada. Rolf Foerster y Sonia Montecino, antropólogos, escribieron "Un Gesto Implacable Guardado en Nuestras Entrañas: Notas Reflexivas sobre una Encuesta Iluminadora”. Ellos ven en los datos una identidad mapuche que se construye en el diálogo con lo no indígena. Esto, "en una sociedad, como la chilena, que ha experimentado (fetichizado) durante siglos el problema mapuche sin encontrarle solución.”

Por último, Juan Ossio, antropólogo peruano, escribió "Encuesta sobre la Identidad de los Mapuche de Chile a la Luz de las Etnias Peruanas". El autor analiza la encuesta a partir de una reflexión sobre los indígenas andinos del Perú, concentrándose en el matrimonio, la residencia, el parentesco y las migraciones como expresiones útiles para conocer mejor la "recreación de la identidad”. 